Daimon. Revista Internacional de Filosofía, n ${ }^{\circ} 85$ (2022), pp. 129-141

ISSN: 1130-0507 (papel) y 1989-4651 (electrónico)

http://dx.doi.org/10.6018/daimon.402751

Licencia Creative Commons Reconocimiento-NoComercial-SinObraDerivada 3.0 España (texto legal). Se pueden copiar, usar, difundir, transmitir y exponer públicamente, siempre que: i) se cite la autoría y la fuente original de su publicación (revista, editorial y URL de la obra); ii) no se usen para fines comerciales; iii) se mencione la existencia y especificaciones de esta licencia de uso.

(c) (1) (9) $\odot$

\title{
¿Emplea Platón el método de Zenón en el Parménides?
}

\section{Does Plato use Zeno's method in the dialogue Parmenides?}

IGNACIO GARCÍA PEÑA*

\begin{abstract}
Resumen: En este trabajo se discute el método de las hipótesis que Platón emplea en la segunda parte del Parménides, el cual, según se dice en el propio diálogo (135d-e), es una réplica del empleado por Zenón de Elea. La discusión es especialmente relevante porque la interpretación de la relación entre las hipótesis sobre lo Uno y el método zenoniano determina el modo en que se entiende el diálogo en su conjunto y las intenciones del autor al redactarlo. Se pretende aquí demostrar la semejanza entre los métodos de ambos filósofos y su utilidad en el filosofar platónico.

Palabras clave: hipótesis, método, Parménides, uno, Zenón
\end{abstract}

\begin{abstract}
This paper discusses Plato's method of hypotheses in the second part of the dialogue Parmenides, which is supposed to be a replica of Zeno's, as stated in the dialogue itself (135d-e). The discussion is highly relevant because it determines the way the dialogue is interpreted as a whole, as well as its author's intentions. Furthermore, this will serve to demonstrate the resemblance between the method of both philosophers and its usefulness in Plato's philosophy.

Keywords: hypotheses, method, Parmenides, one, Zeno
\end{abstract}

\section{Introducción: la $\gamma u \mu v \alpha \sigma i ́ \alpha$ del Parménides}

El Parménides platónico plantea cuestiones muy interesantes desde el punto de vista metodológico, teniendo en cuenta la estructura del diálogo y especialmente de la parte final, en la que se discuten las ocho (o nueve) hipótesis acerca de lo Uno. Una de las más interesantes es la que discutiremos a continuación, a propósito de la relación entre el método empleado en esa importante sección de la obra y el estilo argumentativo de Zenón de Elea.

Después de las objeciones planteadas a la teoría de las Formas, encontramos un pasaje que resulta clave para la interpretación general del diálogo y de esta peculiar relación

Recibido: 12/11/2019. Aceptado: 22/07/2020.

* Profesor Contratado Doctor del Departamento de Filosofía, Lógica y Estética de la Universidad de Salamanca (nachogp@usal.es). Sus principales líneas de investigación son la filosofía griega y helenística y, más específicamente, el pensamiento de Platón. Entre sus publicaciones recientes se encuentran: García Peña, I. (2017), "Los tropos de Agripa: sobre la refutación del fundamento de todo conocimiento", Pensamiento: Revista de investigación e Información filosófica, vol. 73, núm. 276, pp. 255-270; García Peña, I. (ed.) (2019), El Sócrates de Platón. Apología y Critón. Madrid: Tecnos. 
entre Platón y Zenón. En 135c-d, Parménides dirige a Sócrates un reproche de carácter metodológico, ya que ha pretendido definir (ó@í $\zeta \varepsilon \sigma \theta \alpha$ ) las Formas sin el imprescindible entrenamiento previo ( el resto del diálogo, consiste en el ejercicio minucioso de la dialéctica que contempla todas las hipótesis y extrae sus conclusiones. Por otra parte, como señalan Cornford $(1989,167)$ o Guillermo de Echandía $(2005,83)$ en su traducción, parece haber una alusión al procedimiento socrático reflejado en los diálogos de juventud e incluso a los propios diálogos

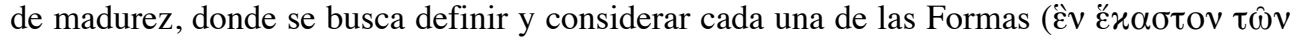

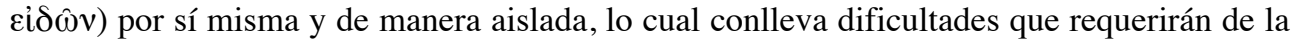

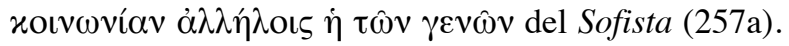

Cuando Sócrates, algo perplejo, pregunta a Parménides en qué consiste esa $\gamma \cup \mu v \alpha \sigma i ́ \alpha$, cuál es el ejercicio que debe practicar, le responde que es el mismo que ha escuchado a Zenón, a pesar de que será el propio Parménides quien lo emplee a continuación. Sin embargo, aunque la declaración no puede ser más explícita, muchos lectores e intérpretes del Parménides, amparándose en el discutible empleo de opiniones y métodos ajenos en muy diversos pasajes de los diálogos platónicos, se preguntan si los ejercicios de la parte final de la obra se corresponden verdaderamente con el método de Zenón. No en vano, como señala Allen $(1964,148)$, no solo debemos tener presente, como en cualquier texto platónico, que se trata de un diálogo con escenas y personajes y no de un tratado filosófico, sino que, además, el Parménides resulta particularmente curioso, teniendo en cuenta que el gran filósofo de Elea parece aceptar una tesis ajena, la platónica de las Formas, y criticar la propia del Ser Uno. Más aún, en contra de la imagen habitual de ambos filósofos, es Zenón quien parece defender una tesis precisa, mientras Parménides se dedica a presentar aporías y argumentaciones contradictorias.

Así pues, podemos responder, en primer lugar, con un sí a la pregunta, aunque la valoración que hagamos de tal método dependerá en buena medida de nuestra consideración del diálogo en su conjunto, pues puede verse en él un ejercicio sistemático del que extraer sólidas conclusiones o un conjunto de argumentos confusos que no llevan a ninguna parte.

Se plantean entonces dos posibilidades: primero, que Platón esté realizando una crítica al método de Zenón, mostrando que su modo de proceder puede generar contradicciones sean cualesquiera las hipótesis que tomemos como punto de partida. Se trataría de un estilo erístico y antilógico muy próximo a las argumentaciones que tantas veces censura y denomina sofístico ${ }^{1}$. A este respecto, es sugerente el comentario de Grote (2009, 290), según el cual, si estos mismos argumentos sutiles nos hubieran llegado bajo el nombre de Euclides de Megara, Protágoras o Gorgias, los críticos los habrían despreciado como producciones pobres dignas de tales sofistas, que comercian y hacen negocio pervirtiendo la verdad.

En segundo lugar, puede pensarse que el método que se emplea en el diálogo es el mismo que el de Zenón, aunque no se utiliza del mismo modo. En el propio texto encontramos una referencia al respecto, en el párrafo 135e, en que Parménides alaba el hecho de que Sócrates

1 Además del pasaje del Eutidemo que se mencionará más adelante, Platón distingue en Menón, 75c-d, la dia-

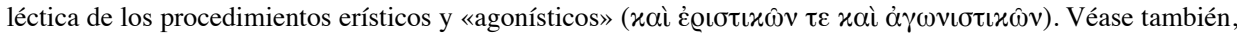
Fedón, 101e; República, 454a y 539b; Filebo, 17a. De acuerdo con Robinson (1941, 88-92), el énfasis puesto por Platón en este asunto se debe precisamente a su proximidad con la dialéctica, aunque esta busque la verdad, mientras los otros métodos se limitan a la controversia, la disputa y la contradicción. 


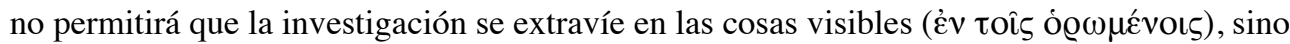

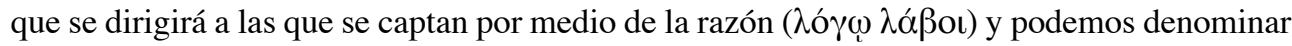
Ideas o Formas ( $\left(\varepsilon_{i} \delta \eta\right)$. Se trataría, así pues, de la misma estructura de razonamiento, aunque con un contenido inteligible en lugar de sensible.

Cabe destacar, no obstante, el hecho de que, en varios pasajes de la obra, y especialmente en la segunda hipótesis, los razonamientos no solamente recuerdan a la típica argumentación de Zenón, sino que incluso parecen presentar las objeciones habituales respecto a la divisibilidad de lo visible y corpóreo. Al atribuirle al Uno el Ser se genera una

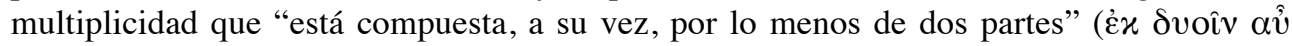

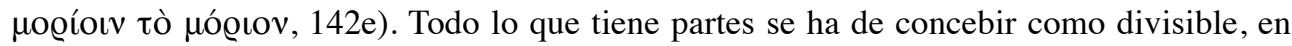
la medida en que resulta ser un agregado de dichos elementos constituyentes. Cada una de sus partes necesariamente incluirá tanto el Ser como la Unidad, con lo cual se llevará este razonamiento hasta el infinito y se llegará a la conclusión de que lo uno es una multiplicidad

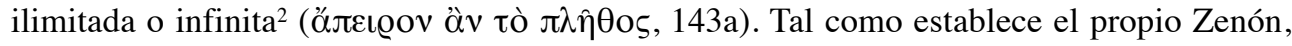
(Simplicio, Fís., 141, 5, DK 29 B 1): "Es lo mismo decir esto una vez y decirlo siempre"

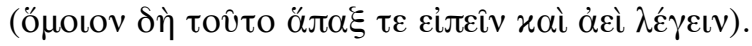

Una variante de esta interpretación, también bastante habitual, es la de considerar que el método argumentativo es zenoniano y que Platón lo considera apropiado como modo de razonamiento. Las contradicciones y perplejidades se deberían, en este caso, a evidentes ambigüedades en el empleo de los términos y las proposiciones que se discuten, siendo así que las falacias y argumentos defectuosos que encontramos en la deliberación no son causados por una mala argumentación, es decir, por la forma, sino por el contenido, variable y ambiguo, de las proposiciones que se discuten.

Por otra parte, quienes tienden a encontrar conclusiones definidas en el procedimiento de la segunda (o tercera) parte del Parménides, suelen considerar que Platón incluye elementos ajenos a la dialéctica zenoniana, ofreciendo un método más amplio y filosóficamente fructífero, como indica, por ejemplo, Cornford $(1989,168-172)$. Esta postura implicaría afirmar que el método del Parménides de Platón no es el método de Zenón. Es el caso, por ejemplo, del excelente estudio de Palmer $(1999,102)$, quien piensa que el método empleado en el Parménides es más complejo porque examina tanto una hipótesis como su negación, mientras Zenón se limita a extraer contradicciones partiendo de una sola tesis. Sería, a su juicio, una adaptación del estilo del filósofo de Elea que, a diferencia de lo que quizá pretenda Platón, tiene el objetivo explícito de generar perplejidad y contradicción, como señalaremos más adelante.

\section{El método de Zenón}

Antes de continuar, por lo tanto, hemos de plantear necesariamente una cuestión adicional: ¿En qué consiste exactamente el método de Zenón? Lo curioso de la pregunta es que, para responderla, además de ciertos testimonios de Aristóteles o Simplicio, el propio

2 Subsiste aquí la misma ambigüedad que en la discusión acerca del concepto de participación, entendiendo al Ser Uno como una magnitud divisible, al modo de la línea de Zenón, razonando acerca de entidades inteligibles del mismo modo que acerca de los objetos materiales. 
Parménides platónico constituye una de las fuentes fundamentales, siendo así que la gran mayoría de análisis de autores posteriores dependen precisamente de estos pasajes.

Sin duda, los razonamientos más conocidos de Zenón son las cuatro aporías o paradojas que Aristóteles critica en el libro VI de la Física (239b) y que suponen un ataque a la concepción habitual, o tal vez también a determinadas propuestas pitagóricas, acerca del movimiento y la pluralidad. Tales argumentos suelen conciliarse, como hemos mencionado, con el pasaje de nuestro diálogo en el que Sócrates (128b) afirma que Parménides y Zenón defienden una misma tesis, aunque por derroteros diferentes, pues mientras el uno afirma la unidad, el otro niega la pluralidad.

No obstante, considero que, si tenemos en cuenta el conjunto de testimonios sobre Zenón, e incluso si analizamos los pasajes de Platón y Aristóteles con cierto detenimiento, no necesariamente hemos de llegar a la conclusión de que Zenón es un mero escudero de Parménides, que defiende la unidad de lo real atacando los argumentos de sus adversarios, reduciendo al absurdo las hipótesis de los defensores de la pluralidad. Tal como indica con inteligencia Jonathan Barnes (1979, 4), el relato tradicional hace de Parménides un monista, defendido indirectamente por Zenón y de manera directa y en prosa argumentativa por Meliso $^{3}$. Y aunque aquí solo tratemos la cuestión de una manera tangencial, sí merece la pena mencionar estudios como los de Néstor Luis Cordero (1991) o Luis Andrés Bredlow (2011), que también cuestionan el relato historiográfico de la continuidad de la llamada "Escuela de Elea" ${ }^{4}$, así como su supuesta defensa del monismo o de la existencia del Uno; término que, como se sabe, tan solo aparece una vez en lo conservado del poema de Parménides 5 . De hecho, no solo se pone en cuestión la interpretación de Zenón como un defensor de lo Uno a través de reducciones al absurdo, sino el modo tradicional de entender a Parménides, que depende en gran medida de estas mismas páginas platónicas.

Siguiendo esa línea de argumentación, Mariana Gardella $(2016,21)$ presenta el método zenoniano dotándolo de un carácter incluso más comprehensivo y corrosivo y señala que

3 Suscribimos sus incisivos comentarios acerca de los filósofos de Elea: “it is wrong to read Zeno's attacks on pluralism as an indirect defence of monism: to argue against pluralism is not - witness Gorgias - to argue for monism; and several of the weapons in Zeno's armoury are, notoriously, effective against monists and pluralists alike. A strand of the ancient doxography suggests that Zeno was a destructive antilogician, not a conservative defender of the Eleatic establishment. Against that suggestion we have only Plato's celebrated story at the beginning of Parmenides; and I sympathise with the view that there is more genial invention in that tale than most scholars are willing to allow".

4 Respecto a la relación de los tres filósofos que, de acuerdo con la mayoría de las explicaciones habituales, conforman la citada escuela, Cordero (1991, 113-115) llega a cuestionar la existencia de un vínculo filosófico entre Parménides y Zenón, ya que bien podría tratarse de una ficción literaria, de un recurso habitual en los textos de Platón, quien presenta una escena con personajes que jamás se conocieron. Bredlow (2011, 31-32), por su parte, concluye que: "Platón confunde sistemáticamente las enseñanzas de Parménides con las de su discípulo putativo Meliso, y, por añadidura, atribuye la invención de este híbrido samio-eleático a Jenófanes. El Teeteto, el Parménides y, para Jenófanes, el Sofista son los primeros documentos de esa confusión o conflación, que luego repetirán Aristóteles, Teofrasto y los doxógrafos".

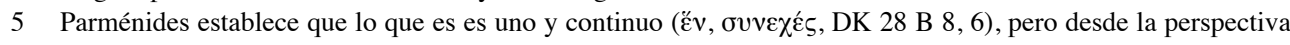
zenoniana, como bien indica Rapp $(2006,181)$ la continuidad resulta incompatible con la unidad, puesto que la torna divisible. No obstante, como muy bien apunta Bredlow $(2011,30)$, la carencia de discontinuidad parece referirse, en este contexto, tras señalar que lo que es nunca fue ni será, a la ausencia de decurso temporal divisible en momentos sucesivos más que a la continuidad corpórea y espacial. 
Zenón no utiliza la reductio ad absurdum como técnica de refutación, dado que si bien parte de hipótesis de las cuales deduce consecuencias contradictorias, no da el paso característico de toda reductio, que es la afirmación de la falsedad de la tesis inicial y la verdad de la tesis contraria. Como se ve en el Parménides, Zenón establece que no existe la multiplicidad, sin por ello afirmar expresamente la existencia de la unidad.

De hecho, si acudimos a algunos otros testimonios antiguos acerca del método y el pensamiento del filósofo, encontramos una postura bastante diferente a la de la interpretación clásica del poema parmenídeo que, por otra parte, como ya se ha indicado, reflexiona sobre lo que es, la generación y la corrupción y no tanto sobre la cuestión de la unidad y la pluralidad. Los fragmentos A 16 y A 21 apuntan claramente a la dirección indicada, haciendo de Zenón, como señala Livio Rossetti (2011), un "filósofo sin filosofía", un discutidor capaz de demostrar cualquier tesis. En este caso, algunos testimonios, como el de la epístola 88 de Séneca a

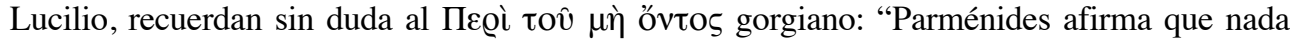
de lo que se ve pertenece al todo; Zenón de Elea eliminó todas las dificultades respecto del asunto, pues dijo que nada existe". Y continúa: "Si creo a Parménides, nada existe, excepto lo uno; si creo a Zenón, ni siquiera existe lo uno". (Cartas a Lucilio, 88, 44-45; DK 29 A 21).

Volviendo al texto de Platón, resulta razonable la interpretación de Palmer (1999, 100), cuando establece que no hay contradicción entre el acierto de Sócrates al caracterizar el libro de Zenón como un ataque a los defensores de la pluralidad y su error al creer que eso implica una defensa de la tesis parmenídea. En 128d, el filósofo afirma literalmente que, si se analizan con detenimiento, las consecuencias que se siguen de la hipótesis "existe la

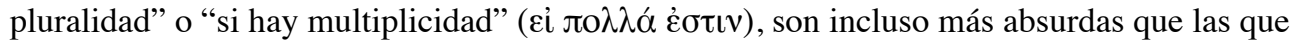

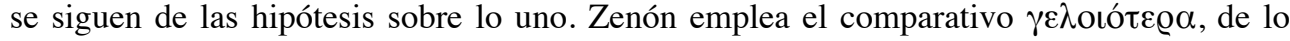
cual podemos deducir que, según su parecer, de la hipótesis sobre lo uno también se siguen consecuencias extrañas, aunque no lo sean tanto.

Debe tenerse presente, además, que, aunque sea habitual leer en el pasaje $128 \mathrm{c}$ que el libro de Zenón constituyó una defensa de la tesis parmenídea, en realidad se afirma de

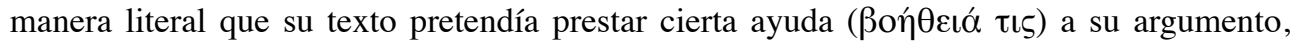
sin explicitar en ningún caso que defienda la misma tesis que el maestro de Elea. Se ha de prestar atención al indefinido, pues se indica que quiso ser de alguna ayuda, prestar algún apoyo. Además, como se apuntó, Zenón está corrigiendo a Sócrates, mostrándole que no ha comprendido completamente el propósito de su texto, que no era otro que un mero afán polémico, propio de la juventud. Palmer $(1999,102)$ cree que el método de Zenón sería una deformación del de Parménides, que trueca la investigación por la competición, ya que además el discípulo se refiere explícitamente a su intención y actividad polémica y com-

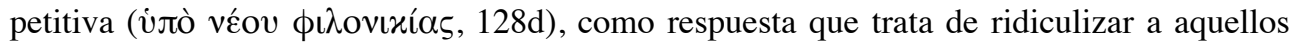
que inicialmente intentaron hacer lo mismo con Parménides. Su venganza no consiste en

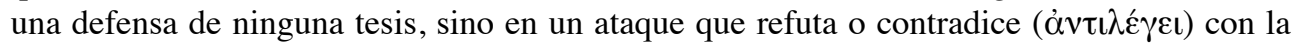

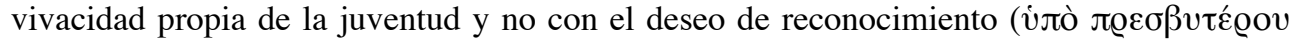

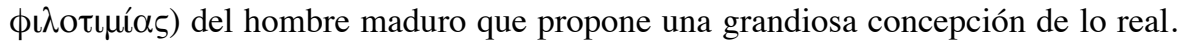

Los argumentos zenonianos, en consecuencia, vendrían a decirnos que, si no se acepta la existencia de la unidad, mucho más difícil será demostrar nada acerca de la pluralidad; lo cual no quiere decir que Zenón esté defendiendo la unidad, sino simplemente estableciendo 
una comparación. Este juicio puede ratificarse sobre una base no muy diferente de lo que se plantea en la hipótesis 4, ya que la propia existencia de la pluralidad depende de la de la unidad (158c). Siendo así, incluso podríamos vincular a Zenón con una argumentación bastante semejante a la de la última página del Parménides, afirmando, en contra de los defensores

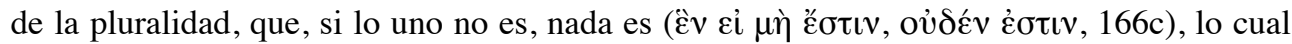
no quiere decir que de la defensa de lo uno no se sigan también consecuencias insostenibles.

Así pues, el método empleado por Platón en el Parménides se asemejaría al de Zenón en mayor medida de lo que cree Palmer, pues el filósofo de Elea abarca un conjunto mucho más amplio de perspectivas de lo que habitualmente se supone. En los argumentos recogidos en la Física aristotélica, las dos primeras hipótesis suponen la infinita divisibilidad del espacio, mientras las otras dos postulan unidades mínimas. Por lo que respecta a la cuestión de lo uno y lo múltiple, Zenón incide en la mayor dificultad de demostrar algo acerca de la pluralidad, pero también señala lo complicado, por no decir imposible, de demostrar la existencia de la unidad. De acuerdo con el testimonio de Simplicio (Fís. 97, 12-13; DK 29 A 16): "Zenón decía que si alguien le explicaba qué es lo uno, sería capaz de dar razón de las cosas que son". Esta afirmación carecería por completo de sentido si hubiese encontrado en el poema parmenídeo la tesis que habitualmente se cree que defiende.

Así pues, el estilo de Zenón es casi idéntico al que se presenta en 136a, donde Parménides propone considerar las consecuencias de una hipótesis, junto con las que se siguen de negarla; no obstante, Zenón parte de la divisibilidad y de la indivisibilidad, de la unidad y de la multiplicidad, con lo cual considera hipótesis contrarias, aunque no estrictamente una afirmación y una negación. Obviamente, solo podemos realizar un intento de reconstrucción necesariamente imperfecto de la filosofía zenoniana, habida cuenta de los escasos testimonios con los que contamos. Parece muy plausible que el libro del que aquí se habla (128d) se corresponda con el texto que recogía cuarenta argumentos del que habla Proclo (DK 29 A 15), por lo que probablemente tan solo se hayan conservado argumentos aislados de un esquema argumentativo mucho mayor. No obstante, sistematizando algunos de los fragmentos y testimonios, podríamos decir que el filósofo de Elea plantea, en primer lugar, lo que se sigue si la unidad es:

1) Si está compuesta de partes y tiene extensión es divisible y, por lo tanto, la unidad no es unidad.

2) Si no tiene magnitud, no puede formarla, con lo cual no puede ser fundamento de la pluralidad.

3) De todo ello se sigue que, si la unidad no es, la pluralidad tampoco.

También es amplio y complejo el esquema de los cuatro argumentos conservados por Aristóteles (Física, 239b) para mostrar la imposibilidad del movimiento. En ellos encontramos dos maneras contrapuestas de concebir el espacio, de las cuales se siguen conclusiones inaceptables. Si el espacio es infinitamente divisible, Aquiles nunca alcanzará a tortuga ni podremos llegar nunca al final de un recorrido, ni a la mitad, ni a la mitad de la mitad, etc. $\mathrm{Si}$, por el contrario, el espacio consta de unidades mínimas, en cada momento la flecha estará inmóvil; además, la velocidad del movimiento resulta indiscernible, pues depende siempre de aquello que tomemos como referencia, resultando así siempre relativa a algo. 
De manera paralela, aunque con una profundidad y unas implicaciones metafísicas aún mayores, el esquema del Parménides platónico podría simplificarse del siguiente modo:

1) Si el Uno es, qué se sigue para el Uno (137c-157b).

2) Si el Uno es, qué se sigue para los otros (157b-160b).

3) Si el Uno no es, qué se sigue para el Uno (160b-164b).

4) Si el Uno no es, qué se sigue para los otros (164b-166c $)^{6}$.

Las conclusiones resultan igualmente desconcertantes, ya que 1) el Uno sería inefable e incognoscible, al mismo tiempo que compuesto de partes e infinitamente divisible. Por otra parte, 2) las otras cosas han de participar de lo Uno para ser múltiples, tanto cada una como conjunto como cada una de sus partes, de modo que se trataría de pluralidades ilimitadas, infinitamente divisibles y poseedoras de todas las cualidades contrapuestas; sin embargo, si no participan de lo Uno, no pueden formar un todo ni tener partes, con lo cual no tendrían existencia. A propósito de lo Uno que no es 3) cualquier cosa que se afirme al respecto ha de ser una verdad relativa a algo que no existe, al tiempo que resulta imposible pensar o decir algo acerca de lo que no es ni tiene ningún tipo de realidad. Con respecto a los otros, si el Uno no es 4) o bien las otras cosas tienen una apariencia de ser, en tanto que solo pueden ser otras entre sí, pero no con respecto a lo Uno, que no existe; o bien, al no haber nada que sea un ente por no existir lo Uno, realmente nada existe, ni siquiera en apariencia.

Puede pensarse que, si bien hay un claro paralelismo entre ambas argumentaciones, tanto por lo que respecta al método como a la dialéctica de la unidad y la pluralidad, la platónica, como se indicó al inicio del diálogo, no se circunscribe al ámbito sensible ${ }^{7}$, por lo que da la impresión de tratarse del mismo método, aunque aplicado a objetos diferentes.

Por todo lo ya indicado, la interpretación general del Parménides, de su objetivo y sus posibles conclusiones, depende en buena parte del modo en que entendamos la relación entre los filósofos de Elea y de la credibilidad que otorguemos al pasaje 128c-d, en el que Platón describe el libro de Zenón como una defensa de la tesis parmenídea. Si Zenón es el discípulo y defensor de Parménides, el método empleado en el diálogo tal vez deba comprenderse como una herramienta para extraer una conclusión, aunque sea a través de negaciones y reducciones al absurdo. Si desvinculamos a ambos pensadores y entendemos el método zenoniano de modo completamente independiente de la defensa de cualquier postulado, la $\gamma u \mu v \alpha \sigma i ́ \alpha$ de la parte final de la obra bien puede entenderse como un juego

6 Versiones diferentes del esquema argumentativo de la segunda parte del diálogo pueden verse, por ejemplo, en Sinaiko (1965) o Tabak (2015). Las clasificaciones podrían multiplicarse atendiendo a las ambigüedades que presenta el propio texto, inicialmente dividido en ocho hipótesis, más el apéndice a la segunda. En cierto modo, parece anticipar aquí, aunque con mucha menor claridad, los usos existencial y predicativo que distinguirá en el Sofista. En ocasiones, la hipótesis tomada como punto de partida "si el Uno es" se transforma en "si el Uno es Uno", por lo que nos encontramos ante una hipótesis y argumentación diferentes. De acuerdo con Kahn (2013,

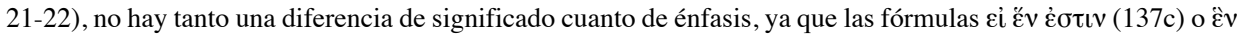

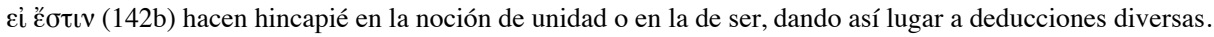

7 De acuerdo con von Fritz $(1975,4)$, el punto de partida de Platón sería precisamente el razonamiento zenoniano explicitado más arriba: "No es difícil ver por qué Platón estaba del todo satisfecho con un argumento de esa clase: porque intentaba probar que lo Uno no podría ser encontrado entre las cosas que tienen magnitud, es decir, en el mundo de extensión espacial; de hecho, no en el mundo de cosas en el espacio y en el tiempo". 
que no defiende ninguna tesis concreta, sino que meramente muestra hipótesis inconsistentes y argumentaciones falaces. En este último caso, a pesar de la elevación metafísica que encontramos en algunos pasajes, el Parménides platónico resultaría más semejante a obras como el Eutidemo que al Sofista o al Filebo.

\section{Conclusión: el uso platónico de las aporías}

Para extraer las conclusiones vincularemos este método con la segunda parte del Fedro, en la que se examina un buen número de procedimientos sofísticos que, en obras anteriores, especialmente el Gorgias, fueron objeto de severas censuras. En el análisis del arte de la palabra de la segunda parte del Fedro se menciona el examen de las almas del auditorio, en función del cual se puede modificar un discurso (271b). También la atención a las cambiantes circunstancias (272a) e incluso un buen número de prácticas que no dudaríamos en llamar "sofísticas" y que parecen haberse criticado y rechazado en obras juveniles. No obstante, Platón las incluye como componentes útiles de ese arte de la palabra, siempre y cuando se parta del requisito primario e ineludible, que es el conocimiento de la verdad acerca de aquello sobre lo que versa el discurso (262c).

El paralelismo con la dialéctica zenoniana del Parménides resulta evidente. El procedimiento por sí solo, como las prácticas sofísticas, puede llevar a múltiples equívocos y servir de herramienta para quienes tengan intención de confundir y engañar. Sin embargo, si se emplea de manera plenamente filosófica, partiendo de la necesaria existencia de las Formas inteligibles, como se indica en 135b-c, aplicándose a lo que se capta por medio del razonamiento en lugar de a los objetos visibles, supondrá un valioso recurso, un ejercicio

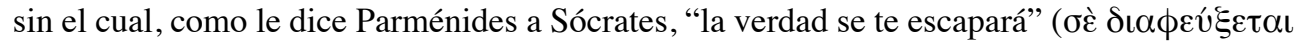

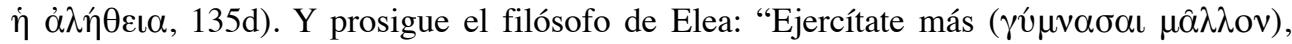
a través de esa práctica aparentemente inútil y a la que la gente llama vana charlatanería

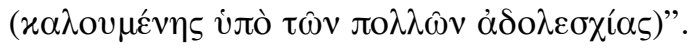

Platón establece así explícitamente que hay quienes opinan que de este ejercicio no se sigue nada provechoso, pero parece evidente que el Parménides platónico de esta escena no se encuentra entre ellos, tal como confirma inmediatamente después.

En esta imaginaria conversación entre el viejo Parménides y el joven e inexperto Sócrates, que supone el momento crítico de su propia filosofía y seguramente el punto de partida del platonismo ${ }^{8}$, Platón elige como interlocutor a Zenón, cuyo método de argumentación le parece útil y eficaz para dar los primeros pasos en la búsqueda de la verdad. No desconoce el procedimiento de reducción al absurdo o la prueba indirecta utilizada por Parménides y secundada por Meliso, que es el auténtico defensor del argumento que Platón continuamente atribuye a aquel, al afirmar con rotundidad la unidad del ser (DK 30 B 5, B 6 y B 9) y negar la existencia del movimiento y de la pluralidad (DK 30 B 8 y B 10), que sólo son percibidas por los sentidos engañosos ${ }^{9}$, en su escrito Sobre el ser. Podría haber hecho

8 Véase Lorite Mena (1992).

9 Este detalle es importante, pues concuerda plenamente con la modificación que Platón realiza en el método de Zenón, no por lo que respecta a su forma, sino a su contenido, puesto que, como ya se ha indicado más arriba, el razonamiento no se aplica al orden de lo sensible sino al de lo inteligible. Siendo así, la indagación del Parménides aplica el método zenoniano, aunque amparándose en la gnoseología de Meliso, como indica Román 
comparecer también a Gorgias, cuyo discurso Sobre el no ser constituye una pieza retórica paradigmática, en la que, sirviéndose de los procedimientos de argumentación y citando sus propias palabras, rebate las conclusiones de Parménides y Meliso $^{10}$. Sin embargo, la retórica sofística ya había sido considerada en el Gorgias como un procedimiento incompleto, que en el Fedro se considera útil en cuanto puede subsumirse en la dialéctica.

Aunque las conclusiones de un diálogo sean imprecisas o hasta inexistentes, no debemos subestimar la importancia de la falacia, de la argumentación errónea, de las aporías ni de las discusiones sin clausura, descalificándolas como simple juego ${ }^{11}$, como procedimiento meramente negativo ${ }^{12}$, limitando la filosofía a un conjunto de conclusiones o a un sistema articulado de tesis. Platón nos está instando a utilizar un método lo más completo posible, que considere todas las hipótesis concebibles, así como las implicaciones de las mismas. Como se indica en numerosos pasajes de los diálogos ${ }^{13}$, conocer algo implica necesariamente la consideración y la comprensión de lo contrario, por lo que el conocimiento de la verdad se ha de entender indisociablemente unido al del error y la falsedad, que incluso pueden constituir una vía indirecta de acceso a aquella.

El método zenoniano no es para Platón un fin en sí mismo, ni debe usarse de cualquier modo, lo cual no quiere decir que sea inútil o que no pueda emplearse con una finalidad filosófica, resultando así valioso y fructífero. Los frutos de todas estas hipótesis que culminan en contradicción no se recogen aquí mismo, sino en ese extraordinario diálogo que es el Sofista, pues, como señala Crombie (2000, 333), uno de los objetivos del Parménides es mostrar que puede extraerse cualquier conclusión si no fijamos con mayor precisión los sentidos en que puede emplearse un término, que constituye precisamente uno de los méritos más celebrados de aquel diálogo, cuando se cometa el parricidio, al "poner a prueba el argumento del padre Parménides y obligar, a lo que no es, a que sea en cierto modo, y, recíprocamente, a lo que es, a que de cierto modo no sea"14. Así, Platón dará un paso más allá, tanto respecto a la filosofía eleática como a la argumentación gorgiana.

Volviendo a la retórica, una de las lecciones habituales que extraemos de los análisis platónicos es el hecho de que no podemos utilizarla como un mero método vacío de contenido,

Alcalá (1994, 187-188): "esta importante variación viene determinada por la necesidad de fundamentar esa reconstrucción de los atributos del «ser» en una gnoseología radical: la crítica a cualquier tipo de conocimiento sensible. Si atendemos a los sentidos, medita Meliso, sólo percibimos cosas cambiantes, movimiento continuo en un mundo de apariencias que configura un mundo contradictorio y falaz donde predomina el tránsito del ser al no-ser. Sin embargo, esta consideración es inaceptable para Meliso, pues la realidad es una e indivisible, no generada y eterna, homogénea, inmóvil y no sujeta a nacimiento o cambio".

10 Un análisis de la importancia de las tesis de Meliso y Gorgias en el Parménides puede verse en Brémond (2019), en el que se defiende que el contenido de las hipótesis, especialmente la primera, se corresponde con lo establecido por Meliso y que Platón emplea el tratado de Gorgias Sobre el no ser para refutarlo.

11 En 137b, justo antes de comenzar con las hipótesis, afirma que deben jugar a este juego laborioso (

12 Es precisamente lo que indica Robinson (1953, 223): "The second part of the Parmenides contains no statement of doctrine, either directly or indirectly”. David Ross $(1993,122)$, aunque sigue esta línea de interpretación, matiza notablemente su postura, señalando que "considerar la «segunda parte» un ejercicio principalmente gimnástico, no excluye la posibilidad de que a lo largo de él se le ocurran ideas positivas a Platón. Ideas que luego fructificarán en su pensamiento posterior".

13 Critón, 48a; Cármides, 171a; Hipias Menor, 366a-367a; Banquete, 223d; República, 333e-334a.

14 Platón, Sofista, 241d. Traducción de N.L. Cordero, en: Platón (1992). 
ni tampoco con independencia de determinados valores morales. Si no se dirige a los objetos adecuados y delimita con precisión el sentido en que se emplean los términos, el procedimiento podrá identificarse con esa $€ \iota ß \eta$ sofística, que desconoce, renuncia o hasta desprecia la verdad sobre el asunto que se trata. Desde luego, no parece que Platón acepte aquello que se menciona en Eutidemo, 272-b, a propósito de la erística, que busca refutar ( $\dot{\varepsilon} \xi \varepsilon \lambda \hat{\varepsilon} \gamma \chi \varepsilon\llcorner v)$

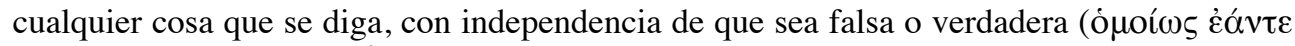
$\left.\psi \varepsilon \hat{v} \delta \sigma_{\varsigma} \dot{\varepsilon} \alpha \dot{v} \tau \varepsilon \dot{\alpha} \lambda \eta \theta \dot{\varepsilon} \varsigma \hat{\eta}\right)$. Considero, sin embargo, que la mención de los sofistas o la vinculación de Zenón con este movimiento no es en absoluto motivo suficiente para pensar que Platón lo desprecia o no lo emplea, ya que es muy consciente de su fecundidad, si se utiliza del modo adecuado y se adapta apropiadamente a la reflexión plenamente filosófica.

En este sentido, podemos hacer un paralelismo con la segunda parte del Fedro y recordar de nuevo lo que se afirma del Palamedes de Elea, que consigue generar la máxima perple-

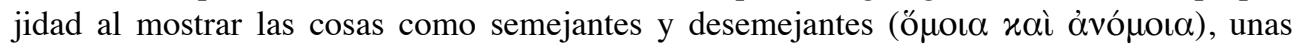

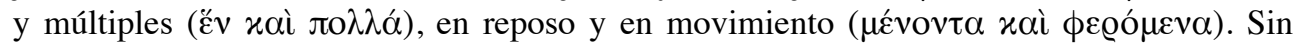
embargo, pregunta Platón, ¿quién realizará mejor este procedimiento que aquel que tiene verdadero conocimiento sobre los objetos de su discurso? (273d) ${ }^{15}$.

Por lo tanto, tal como se anticipa en el Gorgias (465a) y se explicita en el Fedro (260e), el método retórico se muestra inadecuado cuando se emplea como procedimiento formal vacío de contenido ${ }^{16}$. No obstante, si se tiene conocimiento del asunto sobre el que versa el discurso y se practica con una intención noble, puede justificarse y resultar valiosa, como la mentira de la República (389b-c), que Platón no aprueba por sí misma sino, atendiendo a las exigencias mencionadas en esa segunda parte del Fedro, cuando se emplea con el conocimiento apropiado, se dirige a quienes debe dirigirse, atendiendo a la circunstancia y al momento oportuno. La dialéctica de Zenón, como el xaı@ós gorgiano, se incluyen y subsumen en el método platónico, mucho más amplio y ambicioso. Este método zenoniano, siguiendo la metáfora de la gimnasia, no es más que el calentamiento del atleta, antes de comenzar la verdadera competición. Es la necesidad de detectar las dificultades y plantear las aporías como primer paso para descubrir la verdad. La auténtica competición gimnástica, tras el calentamiento retórico, es la dialéctica, tal como se presenta en el Fedro y se aplica en el Sofista, en el que no solo se produce el parricidio de Parménides y la refutación de Meliso, sino que se fulmina el discurso de Gorgias, con la afirmación de la existencia del no ser como diferencia.

Las aporías de Zenón, como todas estas antinomias del Parménides, resultan tan valiosas como esos diálogos de juventud que nos dejan insatisfechos por su falta de conclusión,

15 De hecho, tal como se afirma, por ejemplo, en República, 333e-334a: "el más diestro en dar golpes en la lucha, sea ésta el pugilato u otra cualquiera, ¿no lo es también en guardarse? (...) Y así también, el diestro en guardarse de una enfermedad, ¿no será el más hábil en inocularla secretamente? (...) Y aún más: ¿no será buen guardián del campamento aquel mismo que es bueno para robar los planes y demás tratos del enemigo? (...) Y así, cada uno es buen robador de aquello mismo de lo que es buen guardador (...) Por tanto, si el justo es diestro en guardar dinero, también es diestro en robarlo".

16 Tal como señala Vallejo Campos (1994, 83 y ss.), este aspecto constituye la principal diferencia entre la concep-

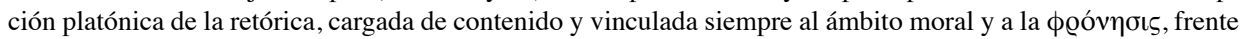
al procedimiento estrictamente formal que, en este sentido y a pesar de otras profundas diferencias, comparten los sofistas y Aristóteles, quien la consideran una herramienta amoral que maneja opiniones. 
ya que suponen el mejor estímulo para continuar buscando por otros caminos ${ }^{17}$, que sí se explorarán en otros diálogos y que, sobre todo, consiguen estimular al lector como el tábano de la Apología (30e) y el pez torpedo del Menón (80a). Siguiendo la línea de Livio Rossetti (2008, 29-30), este método, su aplicación y su finalidad convierten a Zenón en un pensador ciertamente revolucionario en el ámbito filosófico, ya que concibió su función, no tanto como una defesa de Parménides, sino como un intento de estimular la reflexión a través de argumentos paradójicos, el cual, al margen de cristalizar en muchas prácticas sofísticas, sirve refuerzo al filosofar platónico:

Un merecidamente famoso pasaje del Parménides de Platón (128b7-d2) nos obliga a imaginar que Zenón, una vez presentada una paradoja, más que abundar en explicaciones, inferencias y otros elementos metacognitivos, pasaba de inmediato a proponer una segunda paradoja, después una tercera, una enésima, sin dar cuenta de su óptica, sin detenerse sobre su manera de entender sus propias paradojas, sin explicitar el sentido de dichas provocaciones (...) En efecto, parece que su tarea sería sorprender e instalar en los otros una fuerte perplejidad, no explicar.

Acerca del valor de las paradojas y las aporías no solo contamos con el testimonio platónico, puesto que también Aristóteles (Metafísica, 995a-b) incide en la necesidad de plantear y profundizar en ellas antes de intentar solucionar cualquier problema. Aubenque lo considera uno de los rasgos más peculiares del filosofar aristotélico, en el cual no se concibe una búsqueda sin el planteamiento más exhaustivo posible de las aporías, al igual que ocurre en este diálogo gracias al método zenoniano. Más aún, añade al autor francés $(1974,213)$ "resolver una aporía no es eludirla. sino desarrollarla; no es dejarla de lado, sino hundirse en ella y recorrerla de parte a parte".

Los que quieren investigar con éxito han de comenzar por plantear bien las difi-

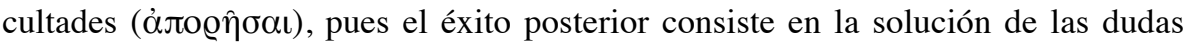

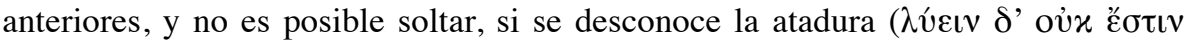

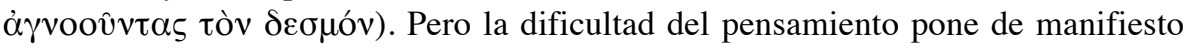
la atadura en relación con el objeto; pues, en la medida en que siente la dificultad, le ocurre algo así como a los que están atados; en ninguno de los dos casos, efectivamente, es posible seguir adelante. Por eso es preciso considerar bien, antes, todas

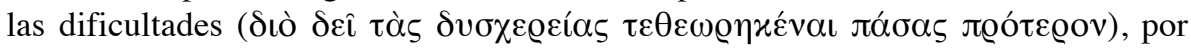
las razones expuestas y porque los que investigan sin haberse planteado antes las dificultades son semejantes a los que desconocen adónde se debe ir, y, además, ni

17 Resulta sumamente sugerente el comentario de Allen $(1997,227)$, que refuerza la tesis de la ausencia de conclusión en el diálogo, al modo zenoniano: "The aim of education is not to impart information but to turn the eye of the soul in the right direction, so that we may see clearly what before had been obscure. One way in which this can be done is by the construction of aporiai, perplexities, and in the concluding part of the Parmenides, this is precisely what we find. The structure is not that of a reductio ad absurdum: indirect proof rests on the logical principle that the contradictory of a self-contradictory proposition is true. The structure of the Parmenides implies that contradiction can be deduced both from a proposition and from its denial, and this extreme of absurdity is, in respect to aporiai, a species of perfection in the art of their statement". 
siquiera conocen si alguna vez han encontrado o no lo buscado; pues el fin no es manifiesto para quien así procede, pero para el que se ha planteado antes las dificultades sí es manifiesto.

En definitiva, el camino hacia la verdad no es sencillo ni directo, sino que nos obliga a dar rodeos y a transitar caminos que no llevan a ninguna parte. Sin embargo, explicitando todos los senderos argumentativos, afirmativos y negativos, como se hace en el Parménides, nos hacemos conscientes del conjunto de posibles dificultades, paso imprescindible, como se ha visto, para la resolución de cualquier problema. Tal como señala el propio Zenón en la hermosa frase de 136e: "La gente ignora, en efecto, que sin recorrer y explorar todos los caminos es imposible dar con la verdad y adquirir inteligencia de ella"

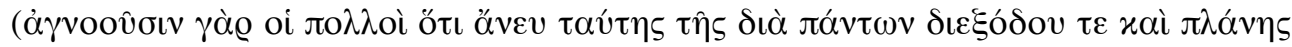

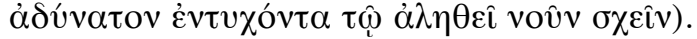

Por último, parece pertinente terminar haciendo hincapié en este concepto de $\pi \lambda \alpha ́ v \eta$, destacando ese elemento zenoniano del filosofar platónico que sugiere que, sin errores, extravíos, digresiones y cursos errantes, no es posible hallar el camino correcto que nos acerque a la verdad.

\section{Bibliografía}

Allen, R.E. (1997), Plato's Parmenides, New Haven and London: Yale University Press.

Allen, R.E. (1964), «The Interpretation of Plato's Parmenides: Zeno's Paradox and the Theory of Forms», Journal of the History of Philosophy, 2, 2, pp. 143-155.

Aubenque, P. (1974), El problema del ser en Aristóteles, Madrid: Taurus. (Primera edición: Le problème de l'être chez Aristote, 1962)

Barnes, J. (1979), «Parmenides and the Eleatic One», Archiv für Geschichte der Philosophie, $61,1,1979$, pp. 1-21.

Bredlow, L.A. (2011), «Platón y la invención de la Escuela de Elea (Sof. 242 d)», Convivium, 24, 2011, pp. 25-42.

Brémond, M. (2019), «Mélissos, Gorgias et Platon dans la première hypothèse du Parménide», Revue de philosophie ancienne 37, 1, pp. 61-99.

Brumbaugh, R.S. (1961), Plato on the One. The Hypotheses in the Parmenides, New Haven: Yale University Press.

Cordero, N.L. (1991), «L'invention de l'école éléatique (Platon, Sophiste, 242 D)», en Aubenque, P. (ed.), Études sur le 'Sophiste’ de Platón, Nápoles: Bibliopolis, pp. 91-124.

Cornford, F.M. (1989), Platón y Parménides, Madrid: Visor. (Primera edición: Plato and Parmenides. Parmenides' Way of Prnth and Plato's Parmenides, 1939).

Gardella, M. (2016), «Antilogía y gimnasia intelectual. La Interpretación de Platón sobre Zenón de Elea», Méthexis, 28, pp. 14-32.

Gardella, M. (2015), «El testimonio de Aristóteles sobre Zenón de Elea como un detractor de lo Uno», Eidos, 23, pp. 157-181.

Grote, G. (2009), Plato and the Other Companions of Sokrates, vol. II, Cambridge and New York: Cambridge University Press. (Primera edición, 1865) 
Kahn, C.H. (2013), Plato and the Post-Socratic Dialogue, Cambridge and New York: Cambridge University Press.

Lorite Mena, J. (1992), «El Parménides de Platón: ¿parricidio o suicidio?», Daimon, 4, pp. 5-17.

Meinwald, C.C. (1991), Plato's Parmenides, Oxford and New York: Oxford University Press.

Nuño, J.A. (1962), La dialéctica platónica. Su desarrollo en relación con la teoría de las Formas, Caracas: Universidad Central de Venezuela.

Palmer, J.A. (1999), Plato's Reception of Parmenides, Oxford: Clarendon Press.

Platon (1992), Diálogos, V(Parménides, Teeteto, Sofista, Político), trad. de M. I. Santa Cruz, A. Vallejo Campos y N. L. Cordero, Madrid: Gredos.

Platón (2005), Parménides, trad. de G. R. de Echandía, Madrid: Alianza.

Rapp, C. (2006), «Zeno and the Eleatic Anti-Pluralism», en Sassi, M. (ed.). La costruzione del discorso filosofico nell'età dei Presocratici, Pisa: Ed. della Normale, pp. 161-182.

Robinson, R. (1941), Plato's Earlier Dialectic, Ithaca and New York: Cornell University Press.

Patterson, R. (1999), «Forms, Fallacies, and the Functions of Plato's Parmenides», Apeiron, 32, 4, pp. 89-106.

Román Alcalá, R. (1994), «Meliso de Samos: la corrección de la ontología parmenídea y sus inevitables consecuencias escépticas», Endoxa: Series Filosóficas, 3, pp. 179-193.

Ross, D. (1993), Teoría de las Ideas de Platón, Madrid: Cátedra. (Primera edición: Plato's Theory of Ideas, 1951).

Rossetti, L. (2008), «El "drama filosófico", invención del s. V a. C. (Zenón y de los Sofistas)», Revista de Filosofía de la Universidad de Costa Rica, 46, 117-118, pp. 29-38.

Rossetti, L. (2011), «Un filosofo senza filosofia», en Barnes, J., et al., Eleatica 2008: Zenone e l'infinito, Sankt Augustin: Academia Verlag, pp. 171-183.

Sinaiko, H.L. (1965), Love, Knowledge, and Discourse in Plato: Dialogue and Dialectic in Phaedrus, Republic, Parmenides, Chicago and London: The University of Chicago Press.

Tabak, M. (2015), Plato's Parmenides reconsidered, New York: Palgrave Macmillan.

Vlastos, G. (1975), «Plato's Testimony concerning Zeno of Elea», The Journal of Hellenic Studies, 95, pp. 136-162.

Von Fritz, K. (1975), «Zenón de Elea en el Parménides de Platón», Diánoia, 21, 1-11. 